\title{
Radiocarbon
}

\author{
1994
}

\section{CALIBRATION OF ${ }^{14} \mathrm{C}$ HISTOGRAMS1: A COMPARISON OF METHODS}

\author{
AD STOLK, ${ }^{2}$ TORBJÖRN E. TÖRNQVIST, ${ }^{2}$ KILIAN P. V. HEKHUIS, ${ }^{2,3}$ HENK J. A. BERENDSEN ${ }^{2}$ \\ and JOHANNES VAN DER PLICHT 4
}

\begin{abstract}
The interpretation of ${ }^{14} \mathrm{C}$ histograms is complicated by the non-linearity of the ${ }^{14} \mathrm{C}$ time scale in terms of calendar years, which may result in clustering of ${ }^{14} \mathrm{C}$ ages in certain time intervals unrelated to the (geologic or archaeologic) phenomenon of interest. One can calibrate ${ }^{14} \mathrm{C}$ histograms for such distortions using two basic approaches. The KORHIS method constructs a ${ }^{14} \mathrm{C}$ histogram before calibration is performed by means of a correction factor. We present the CALHIS method based on the Groningen calibration program for individual ${ }^{14} \mathrm{C}$ ages. CALHIS first calibrates single ${ }^{14} \mathrm{C}$ ages and then sums the resulting calibration distributions, thus yielding a calibrated ${ }^{14} \mathrm{C}$ histogram. The individual calibration distributions are normalized to a standard Gaussian distribution before superposition, thus allowing direct comparison among various ${ }^{14} \mathrm{C}$ histograms. Several experiments with test data sets demonstrate that CALHIS produces significantly better results than KORHIS. Although some problems remain (part of the distortions due to ${ }^{14} \mathrm{C}$ variations cannot be eliminated), we show that CALHIS offers good prospects for using ${ }^{14} \mathrm{C}$ histograms, particularly with highly precise and accurate ${ }^{14} \mathrm{C}$ ages.
\end{abstract}

\section{INTRODUCTION}

${ }^{14} \mathrm{C}$ histograms are useful for analyzing and interpreting large data sets of ${ }^{14} \mathrm{C}$ ages of geologic, archaeologic or other phenomena (e.g., Geyh 1969; Roeleveld 1974). ${ }^{14} \mathrm{C}$ histograms are obtained by superposition of individual ${ }^{14} \mathrm{C}$ ages, represented by Gaussian distributions with the age as a mean value and a width determined by the standard deviation of the ${ }^{14} \mathrm{C}$ measurement. For a ${ }^{14} \mathrm{C}$ histogram, the height is expressed as an intensity. Fluctuating intensities in ${ }^{14} \mathrm{C}$ histograms, which usually occur on time scales of centuries, enable the inference of changes of the investigated phenomenon. However, fluctuating intensities can have several other causes, which hamper the interpretation of ${ }^{14} \mathrm{C}$ histograms. These include:

1. Overrepresentation of certain periods or areas due to preferential sampling (Geyh 1980). This can be avoided by a careful sampling program and a critical selection of ${ }^{14} \mathrm{C}$ ages.

2. An insufficient number of ${ }^{14} \mathrm{C}$ ages. When the data set used in ${ }^{14} \mathrm{C}$ histogram analysis is considered to be a random population, a minimum of $40{ }^{14} \mathrm{C}$ ages per $1000{ }^{14} \mathrm{C} \mathrm{yr}$ is needed to meet statistical requirements (Geyh 1980; Shennan 1987; Stolk, Hogervorst and Berendsen 1989).

3. Non-linearity of the ${ }^{14} \mathrm{C}$ time scale in terms of calendar years, notably the effect of mediumterm atmospheric ${ }^{14} \mathrm{C}$ variations (wiggles) (Geyh 1971; de Jong and Mook 1981).

Fluctuations of the intensity due to natural ${ }^{14} \mathrm{C}$ variations should be eliminated to obtain ${ }^{14} \mathrm{C}$ histograms suitable for geologic or archaeologic interpretation. Stolk, Hogervorst and Berendsen (1989) recognized two distinct approaches: 1) construction of an uncalibrated ${ }^{14} \mathrm{C}$ histogram prior to correction; and 2) calibration of individual ${ }^{14} \mathrm{C}$ ages preceding superposition. Geyh $(1971,1980)$ used

\footnotetext{
${ }^{1}$ Editors' note: The use of the term "histograms" is under discussion. We are planning to publish our discussion about revision of terms concerning ${ }^{14} \mathrm{C}$ in a forthcoming issue.

2Department of Physical Geography, Utrecht University, P.O. Box 80115, NL-3508 TC Utrecht, The Netherlands

3Present address: Waterhoen 5, NL-3831 HT Leusden, The Netherlands

${ }^{4}$ Centre for Isotope Research, University of Groningen, Nijenborgh 4, NL-9747 AG Groningen, The Netherlands
} 
the first approach, but his calculation method was not well documented. Stolk, Hogervorst and Berendsen (1989) also followed the first approach, introduced the KORHIS computer program and discussed their method in detail.

Stuiver and Reimer (1989) constructed ${ }^{14} \mathrm{C}$ histograms using the second approach as an option in the Seattle calibration program (Stuiver and Reimer 1993). The Gliwice program (Pazdur and Michczyńska 1989; Michczyńska, Pazdur and Walanus 1990) also offers an option for the construction of calibrated ${ }^{14} \mathrm{C}$ histograms. However, the Seattle and Gliwice ${ }^{14} \mathrm{C}$ histograms always have the same area, irrespective of the number of ${ }^{14} \mathrm{C}$ ages used, thus inhibiting comparison of intensities of different ${ }^{14} \mathrm{C}$ histograms.

We have found, for very different data sets, that ${ }^{14} \mathrm{C}$ histograms calibrated with KORHIS tend to have similar shapes, with major peaks occurring in the same time intervals. This casts serious doubt on the validity of the KORHIS method. In principle, the two approaches to calibrating ${ }^{14} \mathrm{C}$ histograms should yield the same results. In this paper, we apply the second approach by introducing the CALHIS program, which will be incorporated into the Groningen ${ }^{14} \mathrm{C}$ calibration program (CAL15) (van der Plicht 1993). It is an extension of the summing option of the same program (van der Plicht and Mook 1989). We compare the KORHIS and CALHIS methods to determine whether both approaches can eliminate distortions due to ${ }^{14} \mathrm{C}$ variations. We also discuss the role of other relevant parameters in the calibration of ${ }^{14} \mathrm{C}$ histograms (e.g., standard deviation of the ${ }^{14} \mathrm{C}$ ages, degree of smoothing of the calibration curve).

\section{THE KORHIS METHOD}

The KORHIS method uses the correction factor, $\mathrm{f}\left(\mathrm{f}=\mathrm{dy} / \mathrm{dx} ; \mathrm{dy}={ }^{14} \mathrm{C} \mathrm{yr} ; \mathrm{dx}=\right.$ calendar $\left.\mathrm{yr}\right)$ that is calculated for every 5 th ${ }^{14} \mathrm{C}$ yr. The calculation of the correction factor requires an arbitrary choice for the calibration curve to be used (degree of smoothing) and for the interval width, dy. An uncalibrated ${ }^{14} \mathrm{C}$ histogram is constructed and then multiplied with the correction factor. Stolk, Hogervorst and Berendsen (1989) give full details of this method. The maintenance of the time scale in ${ }^{14} \mathrm{C}$ yr facilitates direct comparison of KORHIS ${ }^{14} \mathrm{C}$ histograms with the corresponding uncalibrated ${ }^{14} \mathrm{C}$ histogram, with published ${ }^{14} \mathrm{C}$ histograms and with single ${ }^{14} \mathrm{C}$ ages.

\section{THE CALHIS METHOD}

Using the CALHIS program, individual ${ }^{14} \mathrm{C}$ ages are calibrated according to the method described by van der Plicht and Mook (1989) and van der Plicht (1993). The Groningen method converts the Gaussian distributions of ${ }^{14} \mathrm{C}$ ages into calibrated distributions, using the calendar age axis as a basis for calculation. Alternatively, one can make these calculations from the ${ }^{14} \mathrm{C}$ age axis. Stuiver and Reimer (1989) and Michczyńska, Pazdur and Walanus (1990) discuss and compare these two procedures and show that the former (the procedure followed by the Groningen program) is the only appropriate method. Dehling and van der Plicht (1993) recently discussed the mathematical background of the Groningen calibration program.

The critical step before the actual construction of calibrated ${ }^{14} \mathrm{C}$ histograms is in the choice of the appropriate calibration curve. Törnqvist and Bierkens (1994) show that the use of a high-resolution calibration curve is justified only in the case of highly precise and accurate ${ }^{14} \mathrm{C}$ ages. Precision is represented by the standard deviation of the measurement error as provided by the laboratory; accuracy is represented by the standard deviation of the natural sample error, which is determined by sample time width and degree of contamination. In nearly all cases, these standard deviations are too large to justify using the high-resolution calibration curve. Therefore, one should use a smoothed version 
of the calibration curve. Törnqvist and Bierkens (1994) discuss the selection of the appropriate calibration curve.

Together with the CALHIS program, a set of 12 calibration curves is supplied, each with different degrees of smoothing. The smoothed calibration curves were constructed with the SMOOTH program, which is also part of the Groningen program, using a Gauss-function for weighting. The smoothing parameter, $\sigma_{\mathrm{s}}$ (the standard deviation of the Gauss-function expressed in cal $\mathrm{yr}$ ), is a measure of the degree of smoothing. Calibration curves can be chosen with values for $\sigma_{8}$ of 10,20 , $30,40,50,60,70,80,100,120,160$ or 200 . The CALHIS program accepts calibration curves ranging from very detailed to very smoothed, and forces the user to choose a conversion file (there is no default). The $\sigma_{\mathrm{s}}=10$ calibration curve corresponds approximately to the high-resolution calibration curve, whereas in the $\sigma_{s}=200$ curve, medium-term ${ }^{14} \mathrm{C}$ variations (wiggles) are completely straightened. The Groningen program provides the possibility of calculating any other smoothed version of the calibration curve, if so desired.

We calculated the 12 calibration curves from the calibration data in the Groningen program, which are identical to those used by Stuiver and Reimer (1993). The calibration curves span the interval $\mathrm{AD} 1950-9440 \mathrm{BC}\left(0-c a .10,000{ }^{14} \mathrm{C}\right.$ yr BP$)$, comprising the entire Holocene period, for which good dendrochronological evidence exists. We have refrained from including calibration data older than $10,000 \mathrm{yr} \mathrm{BP}$, because these are of considerably lower resolution and, hence, not yet suitable for calibrating ${ }^{14} \mathrm{C}$ histograms. However, in principle, CALHIS enables one to construct calibrated ${ }^{14} \mathrm{C}$ histograms up to $16,000 \mathrm{cal}$ yr BP, thus ensuring future extension throughout the Late Glacial.

CALHIS requires an input file, which is in ASCII and consists of ${ }^{14} \mathrm{C}$ ages, their standard deviations, $\sigma_{m}$, and an optional code (e.g., laboratory numbers). CALHIS can produce both uncalibrated and calibrated ${ }^{14} \mathrm{C}$ histograms, and calculates intensities for every ${ }^{14} \mathrm{C}$ yr or cal yr. To construct uncalibrated ${ }^{14} \mathrm{C}$ histograms, the Gaussian distribution of each ${ }^{14} \mathrm{C}$ age is normalized to the area of the standard Gaussian distribution, which is defined as a ${ }^{14} \mathrm{C}$ age with $\sigma_{m}=45$ with an intensity, $\mathrm{I}$, of 1 . To construct calibrated ${ }^{14} \mathrm{C}$ histograms, the Gaussian distributions of equal area (with an $\mathrm{x}$-axis in ${ }^{14} \mathrm{C}$ yr) are converted into calibrated distributions (with an $\mathrm{x}$-axis in cal $\mathrm{yr}$ ). These distributions are normalized to the standard Gaussian distribution, as well. Subsequently, they are summed to a calibrated ${ }^{14} \mathrm{C}$ histogram. The histogram representation can be chosen as "Filled", "Open" or "Dotted". The graphs can be printed directly or saved as a printer file. It is also possible to export the ${ }^{14} \mathrm{C}$ histogram to an ASCII file for further calculation. One can also import the ASCII files in the program to transfer them into histogram graphs.

CALHIS provides the option of selecting other variables, such as the $\mathrm{x}$-axis range in ${ }^{14} \mathrm{C} \mathrm{yr}$ (uncalibrated ${ }^{14} \mathrm{C}$ histograms) or calendar yr (calibrated ${ }^{14} \mathrm{C}$ histograms), or the y-axis range, which represents the intensity. One can also choose the direction of the $\mathrm{x}$-axis to obtain a time axis from left to right or vice versa, thus facilitating comparison with other ${ }^{14} \mathrm{C}$ histograms. In addition, the $\mathrm{y}$-axis can be mirrored, which is useful in the case of two related data sets (cf. Roeleveld 1974). Parts of the $\mathrm{x}$-axis can be selected to focus on interesting time intervals by exaggerating the time scale. The "Building" option gives an onscreen view of the construction of the ${ }^{14} \mathrm{C}$ histogram while it is being calculated. With the "Curve location" option, the standard Gaussian distribution can be placed at any preferred position on the $\mathrm{x}$-axis.

CALHIS will be distributed with a new version of the Groningen ${ }^{14} \mathrm{C}$ calibration program in the near future, and is also available separately upon request. 


\section{EXPERIMENTS}

\section{Test Data Sets}

We composed several test data sets to analyze the ability of the KORHIS and CALHIS programs to reduce the disturbing influence of atmospheric ${ }^{14} \mathrm{C}$ variations in ${ }^{14} \mathrm{C}$ histograms, and to evaluate the role of some other parameters. These include possible effects of different standard deviations $\left(\sigma_{m}\right)$ of the ${ }^{14} \mathrm{C}$ ages and calibration curves with a different degree of smoothing $\left(\sigma_{3}\right)$. The test data sets consist of ${ }^{14} \mathrm{C}$ ages equally distributed over the calendar time scale. The philosophy of this approach is that a calibrated ${ }^{14} \mathrm{C}$ histogram of such a data set has a constant intensity and thus a rectangular shape, provided that the density of ${ }^{14} \mathrm{C}$ ages is sufficient.

We used the data of Stuiver and Pearson (1986), Pearson and Stuiver (1986) and Pearson et al. (1986) to calculate three calibration curves $\left(\sigma_{s}=8, \sigma_{s}=40\right.$ and $\left.\sigma_{s}=200\right)$ using the SMOOTH program (van der Plicht and Mook 1989; van der Plicht 1993). The curve with $\sigma_{s}=8$ is almost identical to the high-resolution calibration curve. The $\sigma_{s}=40$ curve is similar to the $100-\mathrm{cal}-\mathrm{yr}$ curve of Stolk, Hogervorst and Berendsen (1989). The $\sigma_{s}=200$ curve is comparable with a 500-cal-yr curve. Figure 1 shows part of these calibration curves. The period $4500-5500 \mathrm{cal}$ yr BP is characterized by strong, medium-term ${ }^{14} \mathrm{C}$ variations. The curve with $\sigma_{s}=8$ retains all the details of the high-resolution calibration curve. The wiggles are straightened at higher values of $\sigma_{s}$, and are completely lost at $\sigma_{\mathrm{s}}=200$.

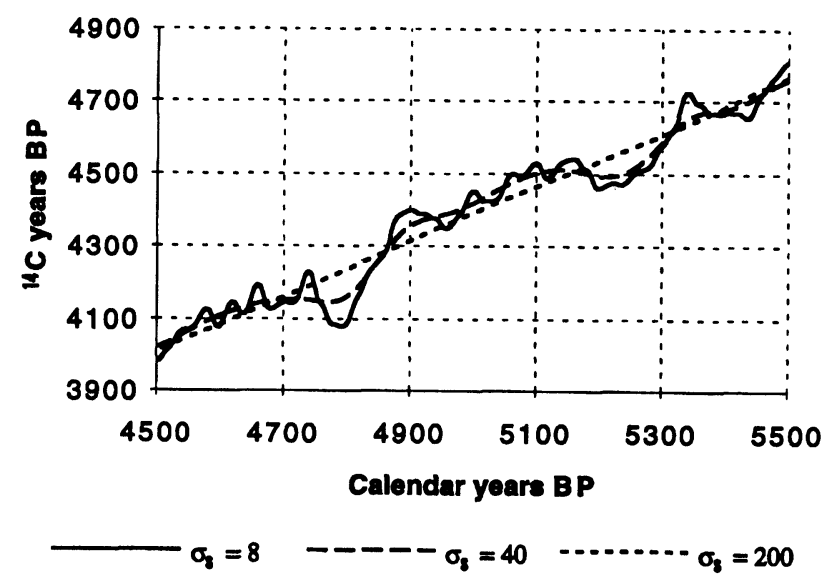

Fig. 1. Examples of calibration curves with different degrees of smoothing for $4500-5500 \mathrm{cal} \mathrm{yr} \mathrm{BP}$

We used the data set obtained from the smoothing with $\sigma_{3}=8$ to create a set of ${ }^{14} \mathrm{C}$ ages whose corresponding calendar ages are equally distributed over the calendar time scale ( 1 for every 5 th calendar yr from $10-7160 \mathrm{cal}$ yr BP). We assigned to the $1431{ }^{14} \mathrm{C}$ ages of this data set standard deviations, $\sigma_{m}$, comparable to those generally provided by ${ }^{14} \mathrm{C}$ laboratories. We used 4 sets of standard deviations: 3 with a constant value $\left(\sigma_{\mathrm{m}}=20, \sigma_{\mathrm{m}}=50\right.$ and $\left.\sigma_{\mathrm{m}}=100\right)$, the 4th consisting of random numbers $\left(\sigma_{\mathrm{m}}=\mathrm{rd}\right)$ with values ranging from 20 to $110{ }^{14} \mathrm{C} \mathrm{yr}$.

Due to specific restrictions of KORHIS, we made a second, slightly different, data set consisting of ${ }^{14} \mathrm{C}$ ages corresponding to every 5th calendar yr from $305-7000 \mathrm{cal}$ yr $\mathrm{BP}$. The $1338{ }^{14} \mathrm{C}$ ages of this data set were rounded to a multiple of 5 and complemented with the same 4 sets of standard deviations. 
The equal spacing of the ${ }^{14} \mathrm{C}$ ages in real time (calendar yr) ensures that fluctuating intensities in uncalibrated ${ }^{14} \mathrm{C}$ histograms of our test data sets are completely due to the non-linearity of the ${ }^{14} \mathrm{C}$ time scale in terms of calendar years. Ideally, one might expect the calibrated ${ }^{14} \mathrm{C}$ histograms constructed from these test data sets to have constant intensities, I, resulting in perfectly rectangular shapes. However, although calibrated ${ }^{14} \mathrm{C}$ histograms generally are closer to the ideal rectangular shape than uncalibrated ones, distortions remain, as Figure 2 illustrates. The variability of the intensity in ${ }^{14} \mathrm{C}$ histograms is represented by the standard deviation, $\sigma_{i}$, of the mean intensity, i (Fig. 2). A measure of the variability of the intensity is the coefficient of variation $\left(V_{c} ; c f\right.$. Shennan 1987), defined as

$$
\mathrm{V}_{\mathrm{c}}=\left(\sigma_{\mathrm{i}} / \overline{\mathrm{I}}\right) \cdot 100[\%] \text {. }
$$

A low value of $\mathrm{V}_{\mathrm{c}}$ corresponds to small distortions due to ${ }^{14} \mathrm{C}$ variations.

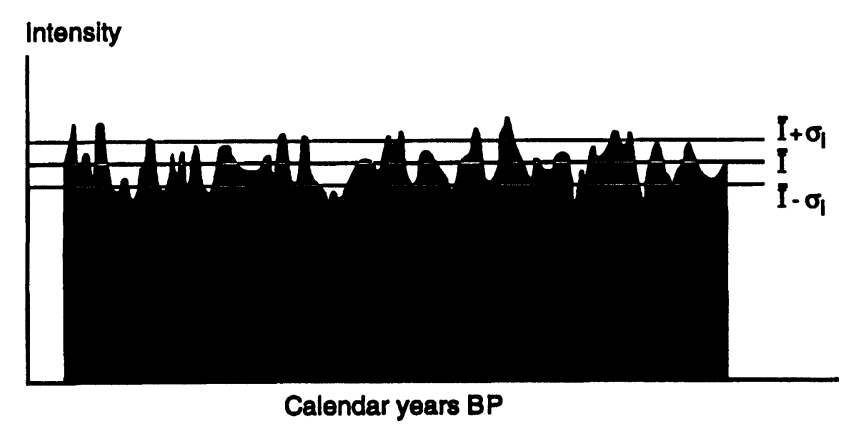

Fig. 2. Schematic representation of $\overline{\mathrm{I}}$ and $\sigma_{i}$ in a calibrated ${ }^{14} \mathrm{C}$ histogram constructed from a test data set

The coefficient of variation $\left(V_{c}\right)$ can be used to compare ${ }^{14} \mathrm{C}$ histograms with different mean intensities constructed by different calibration procedures. Because ${ }^{14} \mathrm{C}$ variations vary in different periods, ${ }^{14} \mathrm{C}$ histograms to be compared must be calculated for the same time intervals. We define the efficiency, $\mathrm{E}$, of the calibration method as the ratio of the coefficients of variation of uncalibrated, $\mathrm{V}_{\mathrm{c}} \mathrm{u}$, and calibrated, $\mathrm{V}_{\mathrm{c}} \mathrm{c},{ }^{14} \mathrm{C}$ histograms

$$
\mathrm{E}=\mathrm{V}_{\mathrm{c}} \mathrm{u} / \mathrm{V}_{\mathrm{c}} \mathrm{c} \text {. }
$$

We calculated this parameter for several ${ }^{14} \mathrm{C}$ histograms constructed on the basis of our test data sets. We calculated values for $V_{c}$ and $E$ for $600-6600 \mathrm{cal} \mathrm{yr} \mathrm{BP}$ in calibrated ${ }^{14} \mathrm{C}$ histograms and for the corresponding interval, $610-5770{ }^{14} \mathrm{C}$ yr $\mathrm{BP}$, in uncalibrated ${ }^{14} \mathrm{C}$ histograms, to avoid marginal effects.

\section{Comparing the Efficiency of KORHIS and CALHIS}

We used the $N=1338$ test data set with four sets of $\sigma_{m}$ for the comparison of KORHIS and CALHIS ${ }^{14} \mathrm{C}$ histograms. We calibrated the ${ }^{14} \mathrm{C}$ histograms with a $\sigma_{8}=40$ calibration curve, because this is the standard calibration curve of the KORHIS program (Stolk, Hogervorst and Berendsen 1989).

Figure 3 shows examples of uncalibrated and calibrated KORHIS and CALHIS ${ }^{14} \mathrm{C}$ histograms. The results for CALHIS show consistently higher efficiencies. Table 1 gives an overview of the statistics of this comparison. Although, in most cases, the general shape of calibrated KORHIS ${ }^{14} \mathrm{C}$ histograms becomes more rectangular than that of uncalibrated ${ }^{14} \mathrm{C}$ histograms, the deviation from 
the ideal shape is obvious and relatively large. For the $\sigma_{\mathrm{m}}=100$ data set, calibration with KORHIS even leads to an increase of the coefficient of variation.

CALHIS cannot eliminate all distortions. Figure 4 shows that the largest distortions in calibrated CALHIS ${ }^{14} \mathrm{C}$ histograms are correlated with steep parts of the calibration curves, showing that some influence of medium-term ${ }^{14} \mathrm{C}$ variations does remain.

KORHIS, uncalibrated

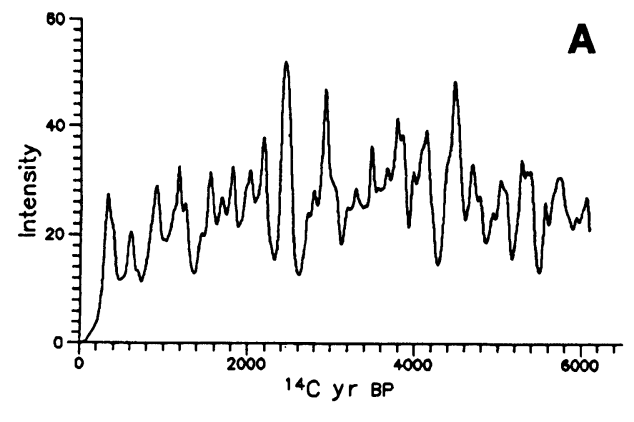

KORHIS, calibrated

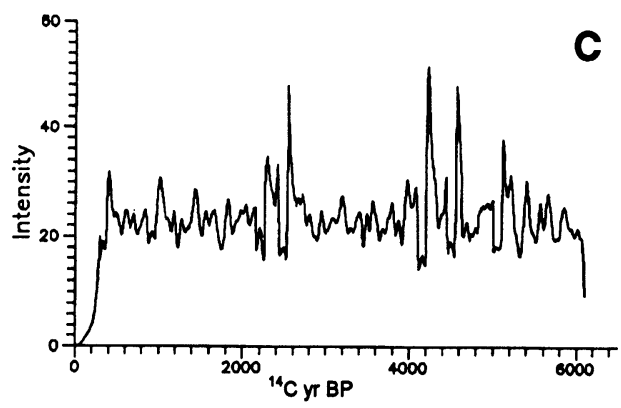

CALHIS, uncalibrated

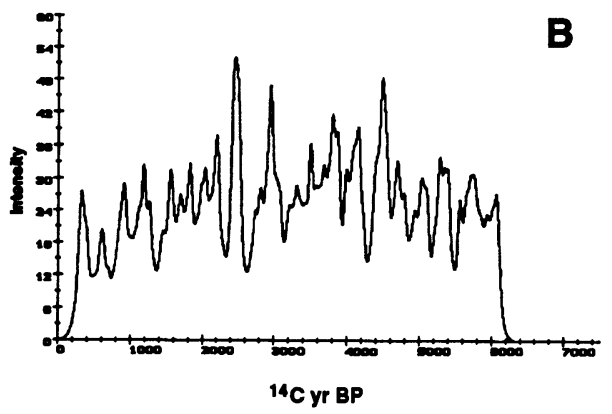

CALHIS, calibrated

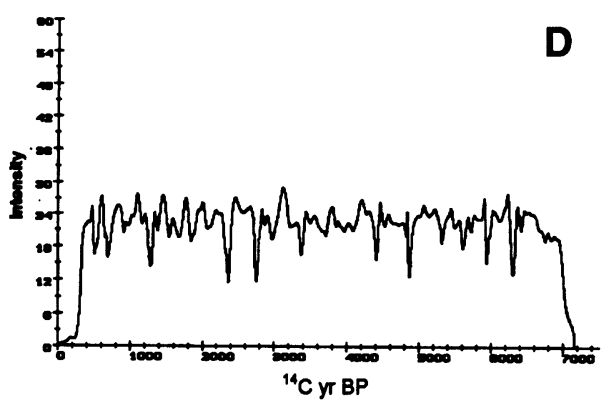

Fig. 3. Examples of ${ }^{14} \mathrm{C}$ histograms constructed with KORHIS and CALHIS. The test data set $\left(\sigma_{\mathrm{m}}=\mathrm{rd}\right)$ used in these ${ }^{14} \mathrm{C}$ histograms is calibrated with a $\sigma_{3}=40$ calibration curve. A. Uncalibrated KORHIS ${ }^{14} \mathrm{C}$ histogram; B. Calibrated KORHIS ${ }^{14} \mathrm{C}$ histogram; C. Uncalibrated CALHIS ${ }^{14} \mathrm{C}$ histogram; D. Calibrated CALHIS ${ }^{14} \mathrm{C}$ histogram. Table 1 gives statistical data for these ${ }^{14} \mathrm{C}$ histograms.

TABLE 1. Coefficient of variation of uncalibrated $\left(V_{c} u\right)$ and calibrated $\left(\mathrm{V}_{c} c\right){ }^{14} \mathrm{C}$ histograms calculated with KORHIS and CALHIS (calibration curve smoothed with $\left.\sigma_{3}=40\right)$ and efficiency $(E)$ of the calibrations

\begin{tabular}{clcccc}
\hline $\mathrm{N}=1338$ & & $\sigma_{\mathrm{m}}=20$ & $\sigma_{\mathrm{m}}=50$ & $\sigma_{\mathrm{m}}=100$ & $\sigma_{\mathrm{m}}=\mathrm{rd}$ \\
\hline \multirow{3}{*}{ KORHIS } & $\mathrm{V}_{\mathrm{c}} \mathrm{u}$ & 52.9 & 32.5 & 17.8 & 29.4 \\
& $\mathrm{~V}_{\mathrm{c}} \mathrm{c}$ & 31.0 & 18.2 & 35.0 & 21.3 \\
& $\mathrm{E}$ & 1.71 & 1.79 & 0.51 & 1.38 \\
& $\mathrm{~V}_{\mathrm{c}} \mathrm{u}$ & 52.9 & 32.5 & 17.7 & 29.4 \\
CALHIS & $\mathrm{V}_{\mathrm{c}} \mathrm{c}$ & 24.6 & 12.7 & 6.3 & 12.8 \\
& $\mathrm{E}$ & 2.15 & 2.56 & 2.81 & 2.30 \\
\hline
\end{tabular}




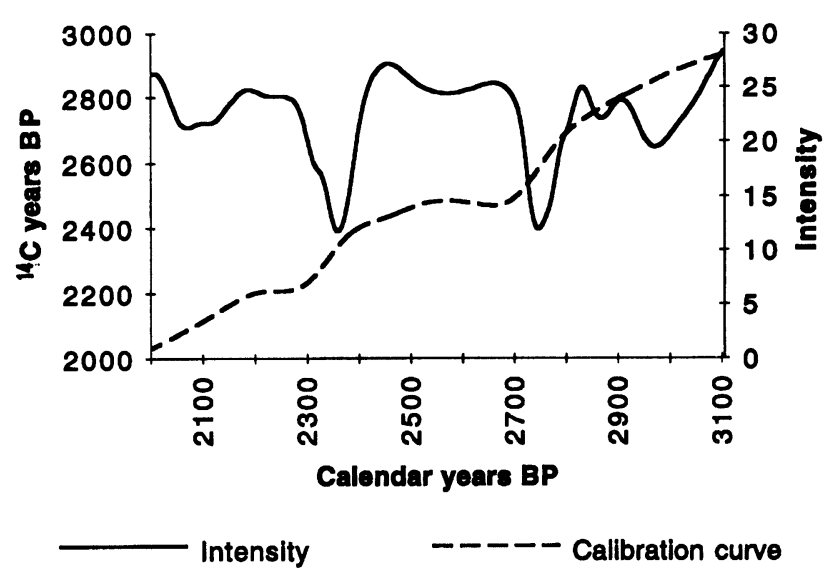

Fig. 4. Relation between distortions in a calibrated CALHIS ${ }^{14} \mathrm{C}$ histogram and the calibration curve. This example shows a part of a ${ }^{14} \mathrm{C}$ histogram calibrated with $\sigma_{s}=40\left(\sigma_{m}=r d\right)$ and the $\sigma_{3}=40$ calibration curve for the same time interval.

\section{The Role of $\sigma_{\mathrm{m}}$ and $\sigma_{\mathrm{s}}$ in the Calibration of ${ }^{14} \mathrm{C}$ Histograms}

We used the $N=1431$ test data set to analyze the role of different standard deviations $\left(\sigma_{m}\right)$ and different degrees of smoothing $\left(\sigma_{s}\right)$ in the calibration of ${ }^{14} \mathrm{C}$ histograms. We constructed 4 uncalibrated ${ }^{14} \mathrm{C}$ histograms consisting of ${ }^{14} \mathrm{C}$ ages with different sets of standard deviations, and calibrated these ${ }^{14} \mathrm{C}$ histograms with three calibration curves $\left(\sigma_{3}=8, \sigma_{3}=40\right.$ and $\left.\sigma_{s}=200\right)$.

The results (Table 2) show that the coefficient of variation of calibrated ${ }^{14} \mathrm{C}$ histograms is consistently lower than that of uncalibrated ${ }^{14} \mathrm{C}$ histograms, indicating that the use of CALHIS is always an improvement. Figure 5 shows the effect of different smoothing parameters of the calibration curve on calibration of ${ }^{14} \mathrm{C}$ histograms. Values for $V_{c} c$ increase with increasing smoothing of the calibration curve. We have included the results for the $\sigma_{s}=200$ calibration curve to show the relatively low efficiency of calibration that is typical for this curve. It should be kept in mind that our test data set is highly accurate because it registers detailed ${ }^{14} \mathrm{C}$ variations. Thus, combining the test data set with a strongly smoothed calibration curve is unrealistic.

TABLE 2. Coefficient of variation of uncalibrated $\left(\mathrm{V}_{\mathrm{c}} \mathrm{u}\right)$ and calibrated $\left(V_{c} c\right){ }^{14} \mathrm{C}$ histograms constructed with different combinations of $\sigma_{m}$ and $\sigma_{s}$ and efficiency $(\mathrm{E})$ of the calibrations

\begin{tabular}{llcccc}
\hline $\mathrm{N}=1431$ & & $\sigma_{\mathrm{m}}=20$ & $\sigma_{\mathrm{m}}=50$ & $\sigma_{\mathrm{m}}=100$ & $\sigma_{\mathrm{m}}=\mathrm{rd}$ \\
\hline \multirow{5}{*}{$\sigma_{\mathrm{s}=8}$} & $\mathrm{~V}_{\mathrm{c}} \mathrm{u}$ & 53.0 & 32.5 & 17.7 & 29.4 \\
& $\mathrm{~V}_{\mathrm{c}} \mathrm{c}$ & 9.8 & 9.1 & 5.6 & 9.8 \\
& $\mathrm{E}$ & 5.41 & 3.57 & 3.16 & 3.00 \\
$\sigma_{\mathrm{s}}=40$ & $\mathrm{~V}_{\mathrm{c}} \mathrm{c}$ & 24.7 & 12.7 & 6.3 & 12.7 \\
& $\mathrm{E}$ & 2.15 & 2.56 & 2.81 & 2.31 \\
$\sigma_{\mathrm{s}}=200$ & $\mathrm{~V}_{\mathrm{c}} \mathrm{c}$ & 49.3 & 27.7 & 10.7 & 24.6 \\
& $\mathrm{E}$ & 1.08 & 1.17 & 1.65 & 1.20 \\
\hline
\end{tabular}




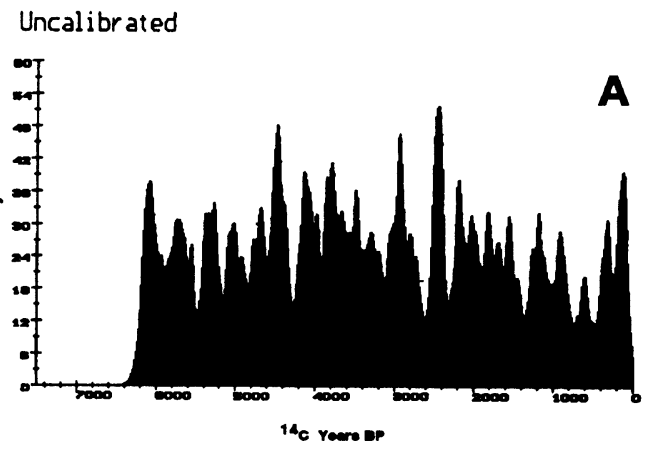

Calibrated, os $=8$

Calibrated, os $=40$
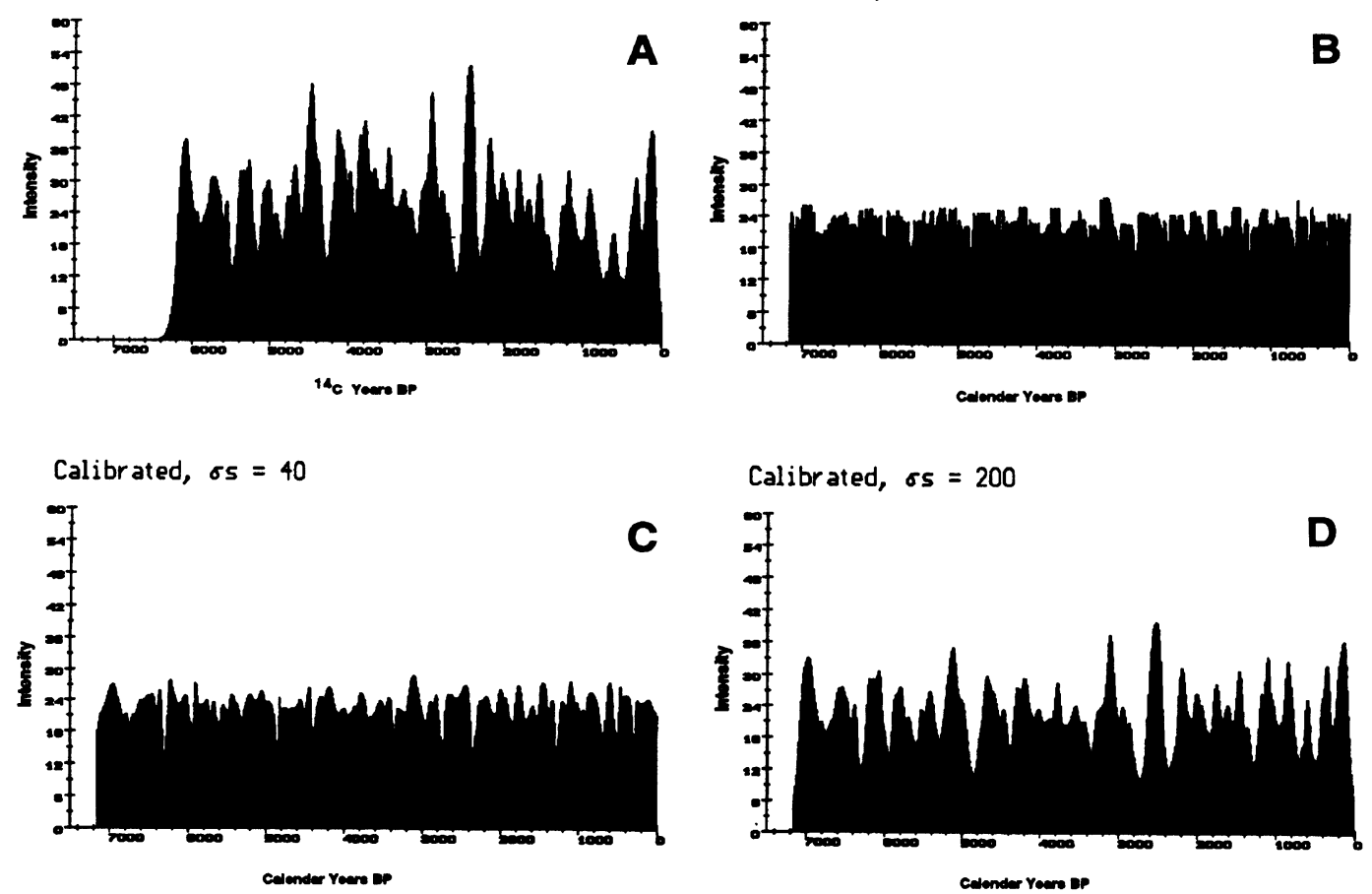

Calibrated, $\sigma s=200$

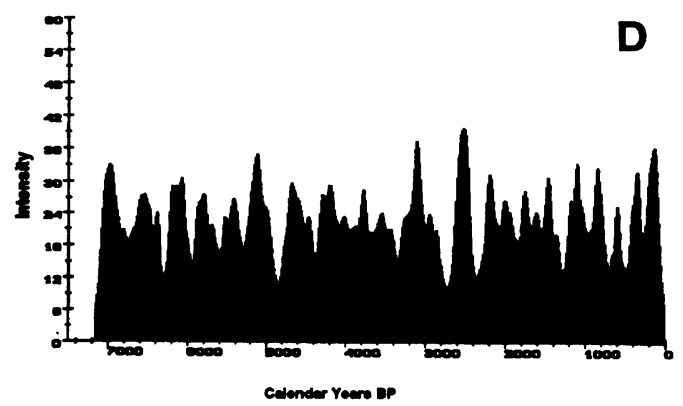

Fig. 5. Examples of CALHIS ${ }^{14} \mathrm{C}$ histograms constructed with the $\sigma_{m}=$ rd data set. A. Uncalibrated; B. $\sigma_{3}=8 ; C . \sigma_{3}=40 ; D$. $\sigma_{\mathrm{s}}=200$. Table 2 gives statistical data for these ${ }^{14} \mathrm{C}$ histograms.

Figure 6 illustrates the effect of different $\sigma_{m}$ values of the test data sets. High efficiencies are found for the relatively precise ${ }^{14} \mathrm{C}$ ages that require a detailed calibration curve (Table 2, Figs. 6A, $\mathrm{B}$ ). Obviously, calibrating ${ }^{14} \mathrm{C}$ histograms with such data is necessary to avoid distortions. This is an interesting conclusion because the number of highly precise and accurate ${ }^{14} \mathrm{C}$ data is expected to increase rapidly in the future. The results for $\sigma_{m}=100$ (Figs. 6C, D) show that the efficiency of the calibration is lower for data sets of ${ }^{14} \mathrm{C}$ ages with large standard deviations, but it is clear that calibration is still worthwhile.

\section{DisCUSSION AND CONCLUSIONS}

The efficiency of calibrating ${ }^{14} \mathrm{C}$ histograms with CALHIS is significantly greater than with KORHIS. Although KORHIS is straightforward, and Stolk, Hogervorst and Berendsen (1989) expected it to yield the same results as CALHIS, it is obviously not the case. Synchronous peaks and troughs in virtually all ${ }^{14} \mathrm{C}$ histograms calibrated with KORHIS indicate the dominance of the correction factor. This prompts speculations about causal relations between natural ${ }^{14} \mathrm{C}$ variations and, for example, geologic changes (e.g., Geyh 1971). However, the dominant correction factor is probably induced by KORHIS, itself. Artifacts are introduced in the double choice requirement: 1) the degree of smoothing of the calibration curve; and 2) the interval width, dy (in ${ }^{14} \mathrm{C} \mathrm{yr}$ ) for calculating the correction factor. Another indication of theoretical problems inherent in KORHIS is that the total area of the ${ }^{14} \mathrm{C}$ histogram before and after calibration may be different. In contrast, an identical area before and after calibration is an important prerequisite in CALHIS. 


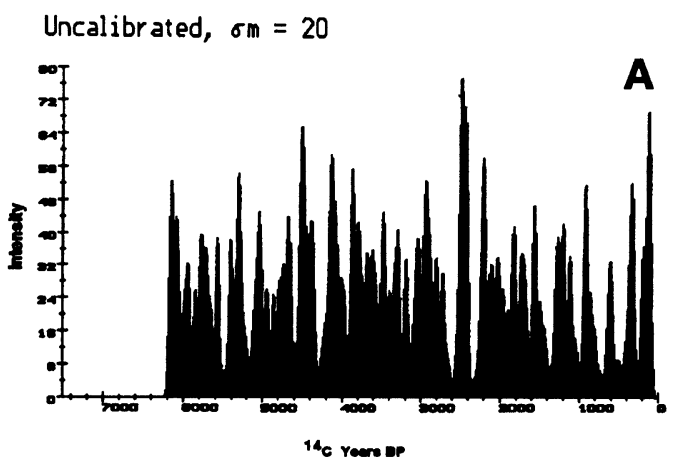

Calibrated, $\sigma m=20$

Uncalibrated, $\sigma \mathrm{m}=100$

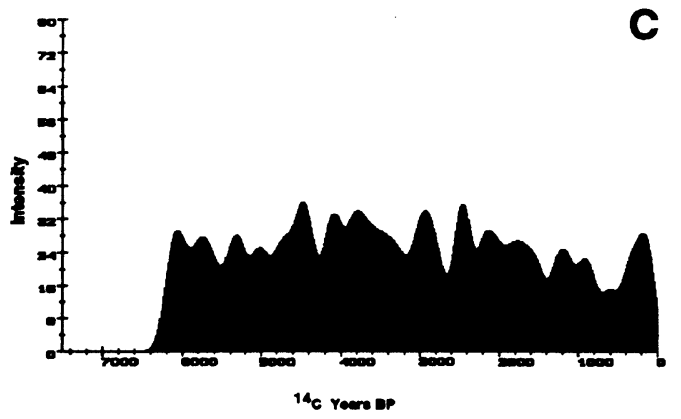

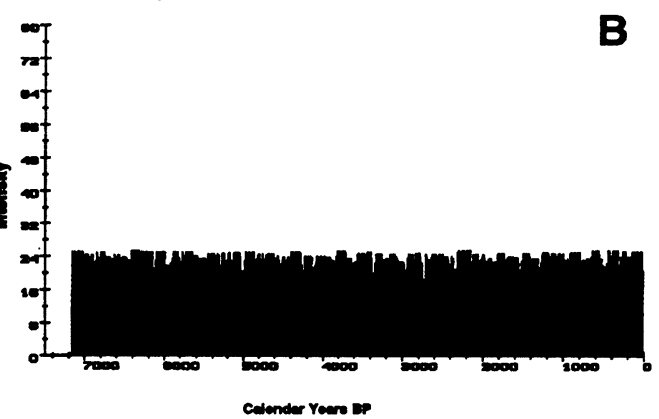

Calibrated, $\sigma m=100$

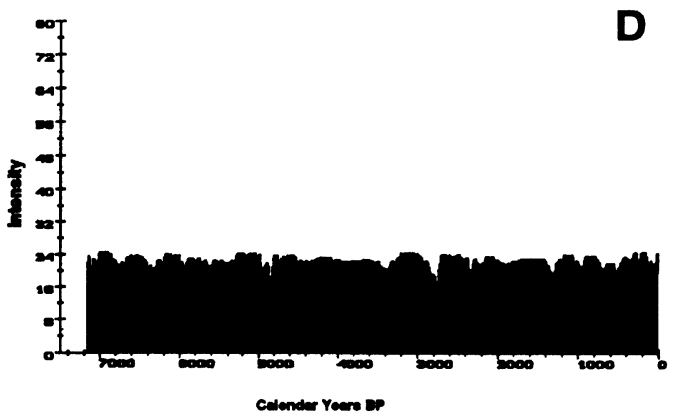

Fig. 6. Examples of CALHIS ${ }^{14} \mathrm{C}$ histograms. A. Uncalibrated, $\sigma_{m}=20$; B. Calibrated, $\sigma_{m}=20$; C. Uncalibrated, $\sigma_{m}=100$; D. Calibrated, $\sigma_{m}=100$. Calibrated ${ }^{14} \mathrm{C}$ histograms $(B$ and $D)$ were constructed with the $\sigma_{3}=8$ calibration curve. Table 2 gives statistical data for these ${ }^{14} \mathrm{C}$ histograms.

Although CALHIS results are significantly better than those of KORHIS, some problems remain. As illustrated by our test data sets, fluctuating intensities are still present in calibrated ${ }^{14} \mathrm{C}$ histograms. Stuiver and Reimer (1989) obtained similar results and concluded that distortion of ${ }^{14} \mathrm{C}$ histograms is unavoidable. The persistent low parts in calibrated ${ }^{14} \mathrm{C}$ histograms correspond to the steepest parts of the calibration curve. Our experiments show that the efficiency of CALHIS is especially high in data sets consisting of accurate and precise ${ }^{14} \mathrm{C}$ ages that require detailed calibration curves. In such cases, calibration is of utmost importance to arrive at ${ }^{14} \mathrm{C}$ histograms suitable for geologic or archaeologic interpretation. Because the availability of accurate and precise ${ }^{14} \mathrm{C}$ ages can be expected to increase considerably in the future, the importance of calibration of ${ }^{14} \mathrm{C}$ histograms will also increase.

The CALHIS program is a useful tool, dedicated to the construction of ${ }^{14} \mathrm{C}$ histograms. It requires the user to choose a suitable calibration curve for their specific data sets. CALHIS options improve graphic presentation and provide possibilities for further calculation.

\section{ACKNOWLEDGMENTS}

Arie de Jong and Marc Bierkens made some important suggestions in the course of this study. This is a contribution to IGCP Project 274, "Coastal Evolution in the Quaternary". 


\section{REFERENCES}

Dehling, H. and van der Plicht, J. 1993 Statistical problems in calibrating radiocarbon dates. In Stuiver, M., Long, A. and Kra, R. S., eds., Calibration 1993. Radiocarbon 35 (1): 239-244.

de Jong, A. F. M. and Mook, W. G. 1981 Natural C-14 variations and consequences for sea-level fluctuations and frequency analysis of periods of peat growth. In van Loon, A. J., ed., Quaternary Geology: A Farewell to A. J. Wiggers. Geologie en Mijnbouw 60: 331-336.

Geyh, M.A. 1969 Versuch einer chronologischen Gliederung des marinen Holozäns an der Nordseeküste mit Hilfe der statistischen Auswertung von ${ }^{14} \mathrm{C}$ Daten. Zeitschrift der Deutschen Geologischen Gesellschaft 118 (1966): 351-360.

1971 Middle and young Holocene sea-level changes as global contemporary events. Geologiska Föreningens $i$ Stockholm Förhandlingar 93: 679692.

1980 Holocene sea-level history: Case study of the statistical evaluation of ${ }^{14} \mathrm{C}$ dates. In Stuiver, $\mathrm{M}$. and Kra, R. S., eds., Proceedings of the 10th International ${ }^{14} \mathrm{C}$ Conference. Radiocarbon 22 (3): 695-704.

Michczynska, D. J., Pazdur, M. F. and Walanus, A. 1990 Bayesian approach to probabilistic calibration of radiocarbon ages. In Mook, W. G. and Waterbolk, H. T., eds., Proceedings of the 2 nd International Symposium ${ }^{14} \mathrm{C}$ and Archaeology. Strasbourg, PACT 29: 69-79.

Pazdur, M. F. and Michczynska, D. J. 1989 Improvement of the procedure for probabilistic calibration of radiocarbon dates. In Long, A., Kra, R. S. and Srdoc, D., eds., Proceedings of the 13 th International ${ }^{14} \mathrm{C}$ Conference. Radiocarbon 31 (3): 824-832.

Pearson, G. W. and Stuiver, M. 1986 High-precision calibration of the radiocarbon time scale, 500-2500 BC. In Stuiver, M. and Kra, R. S., eds., Proceedings of the 12th International ${ }^{14} \mathrm{C}$ Conference. Radiocarbon 28 (2B): 839-862.

Pearson, G. W., Pilcher, J. R., Baillie, M. G. L., Corbett, D. M. and Qua, F. 1986 High-precision ${ }^{14} \mathrm{C}$ measure- ment of Irish oaks to show the natural ${ }^{14} \mathrm{C}$ variations from AD 1840 to 5210 BC. In Stuiver, M. and Kra, R. S., eds., Proceedings of the 12 th International ${ }^{14} \mathrm{C}$ Conference. Radiocarbon 28 (2B): 911-934.

Roeleveld, W. 1974 The Holocene evolution of the Groningen marine-clay district. Berichten van de Rijksdienst voor het Oudheidkundig Bodemonderzoek 24 (Supplement): 1-132.

Shennan, I. 1987 Global analysis and correlation of sealevel data. In Devoy, R. J. N., ed., Sea Surface Studies. A Global View. London, Croom Helm: 198-230.

Stolk, A., Hogervorst, K. and Berendsen, H. 1989 Correcting ${ }^{14} \mathrm{C}$ histograms for the non-linearity of the radiocarbon time scale. Radiocarbon 31 (2): 169-177.

Stuiver, M. and Pearson, G. W. 1986 High-precision calibration of the radiocarbon time scale, AD 1950-500 BC. In Stuiver, M. and Kra, R. S., eds., Proceedings of the 12th International ${ }^{14} \mathrm{C}$ Conference. Radiocarbon 28 (2B): 805-838.

Stuiver, M. and Reimer, P. 1989 Histograms obtained from computerized radiocarbon age calibration. In Long, A., Kra, R. S., and Srdoc, D., eds., Proceedings of the 13th International ${ }^{14} \mathrm{C}$ Conference. Radiocarbon 31 (3): 817-823.

1993 Extended ${ }^{14} \mathrm{C}$ data base and revised CALIB $3 .{ }^{14} \mathrm{C}$ age calibration program. In Stuiver, M., Long, A. and Kra, R. S., eds., Calibration 1993. Radiocarbon 35 (1): 215-230.

Törnqvist, T. E. and Bierkens, M. F. P. 1994 How smooth should curves be for calibrating radiocarbon ages? Radiocarbon (36)1:11-26.

van der Plicht, J. 1993 The Groningen radiocarbon calibration program. In Stuiver, M., Long, A. and Kra, R. S., eds., Calibration 1993. Radiocarbon 35 (1): 231237.

van der Plicht, J. and Mook, W. G. 1989 Calibration of radiocarbon ages by computer. In Long, A., Kra, R. S. and Srdoc, D., eds., Proceedings of the 13th International ${ }^{14} \mathrm{C}$ Conference. Radiocarbon 31(3): 805-816. 